\title{
TOLERÂNCIA E EMANCIPAÇÃO: O LUGAR DA RELIGIÃO NOS PENSAMENTOS DE LOCKE E MARX
}

\author{
TOLERATION AND EMANCIPATION: THE PLACE OF RELIGION IN THE THOUGHTS OF LOCKE \\ AND MARX
}

\author{
Flávio Gabriel Capinzaiki Ottonicar*
}

\begin{abstract}
RESUMO
Locke e Marx são dois exemplos de filósofos que se ocuparam do tema da religião em seus escritos. Na Carta sobre a tolerância, Locke defendeu a indiferença do Estado em relação à questão religiosa, entregando para o indivíduo a liberdade de professar a fé que lhe convenha, segundo suas convicções e seus sentimentos internos. A posição do Estado em relação à multiplicidade religiosa da sociedade não implicaria, assim, em perda ou aquisição de direitos. Marx, por outro lado, reconhece nessa ideia de tolerância um progresso. Porém, no seu texto Sobre a questão judaica, o pensador alemão afirma que a indiferença do Estado em relação às questões religiosas ainda é insuficiente para provocar a verdadeira emancipação humana. Isso porque continua a haver uma religião a ser tolerada pelo Estado e um Estado para tolerar a religião. $\mathrm{O}$ homem, dessa forma, apesar de haver se emancipado politicamente, ainda não se emancipou do Estado, e nem mesmo da religião, o que representa sua emancipação final, a emancipação humana.
\end{abstract}

PALAVRAS-CHAVE: Locke. Marx. Religião. Tolerância. Emancipação.

\begin{abstract}
Locke and Marx are examples of philosophers who carry about the query of religion in their works. In the Letter on Toleration, Locke defended abstention of State on the religious issue and gave to the individual the freedom to profess the faith that suits him, according to his inner conviction and feelings. Therefore, the State's indifference to the religious multiplicity of society would not imply loss or acquisition of rights. Marx, on the other hand, recognizes in this idea of toleration a progress. However, in his text, On the Jewish Question, the German thinker claims that state's indifference to religious matters is still insufficient to bring about true human emancipation. That is because there is still a religion to be tolerated by the state and a state to tolerate religion. Man, in this way, despite having emancipated himself politically, has not yet emancipated himself from the state, and not even from religion, which represents his final emancipation, human emancipation.
\end{abstract}

KEYWORDS: Locke. Marx. Religion. Toleration. Emancipation.

\section{INTRODUÇÃO}

Escritos em circunstâncias completamente diferentes, a Carta sobre a tolerância (1689) e Sobre a questão judaica (1844) têm em comum o fato de se debruçarem sobre a quase sempre conflituosa relação entre as dimensões política e religiosa do ser humano. $\mathrm{O}$

\footnotetext{
* Graduado em Letras, licenciatura português-inglês (2006) e filosofia (2015). Mestrando em filosofia pela Universidade Estadual Paulista. E-mail: fottonicar@gmail.com.
} 
primeiro texto veio a público durante o exílio de John Locke na Holanda e marca a posição do filósofo acerca da questão da tolerância religiosa, tema que estava na pauta de discussão tanto do parlamento inglês quanto dos pensadores europeus. O segundo é um texto publicado por Marx no primeiro e único número dos Anais Franco-Alemães de 1844 em resposta à obra $A$ Questão Judaica, de Bruno Bauer, publicado um ano antes.

Profundamente diferentes entre si, os textos tratam dos desdobramentos frequentemente conflitantes entre a religião e a política como produtos do espírito humano. Cada um a seu tempo e conforme os limites impostos pelas circunstâncias históricas, trata da relação entre política e religião enquanto elementos indispensáveis da existência humana.

Não obstante o abismo temporal, circunstancial e mesmo ideológico que separa os dois textos, têm eles sua razão de ser na necessidade de responder à questão: "qual deve ser o lugar da religião no Estado político?"

Neste trabalho pretendemos analisar e contrapor as respostas dadas por Locke e Marx quanto à posição que deve ser reservada à religião no âmbito do Estado político. Primeiro, nos concentraremos na tolerância que Locke defende através de sua Carta. Em seguida, analisaremos a posição marxista encontrada em Sobre a questão judaica e sua crítica à solução de Bruno Bauer. Por fim, contrapondo as duas abordagens, concluiremos que a crítica de Marx à emancipação política se aplica também a ideia de tolerância defendida por Locke, e que a emancipação humana representa também a superação da necessidade de tolerância religiosa por parte do Estado.

A análise da defesa de Locke da Tolerância deve levar em conta dois fatores contextuais: primeiro, a quebra da unidade cristã ocorrida por meio das reformas protestantes, que deram origem também a vários agrupamentos religiosos menores e segundo, o elo estreito entre o absolutismo monárquico e a religião no contexto da segunda metade do século XVII. É preciso considerar, previamente, que o surgimento de vários agrupamentos cristãos potencializou os conflitos religiosos no interior da sociedade inglesa, dado o forte vínculo do Estado com determinados grupos religiosos.

Entre as décadas de 1630 e 1680, a Inglaterra teve governantes ligados a diversas religiões. Carlos I, que foi executado em 1641, era anglicano. Foi sucedido, em um curto período republicano, por Oliver Cromwell, que confessava o puritanismo. Ao restaurar-se a 
monarquia, sobe ao trono outro monarca anglicano, Carlos II. Por fim, seu sucessor, o último monarca de tendências absolutistas, Jaime I, era católico. Nesse cenário, foi frequente a alternância de grupos religiosos que ora eram preferidos pelo governo, ora eram perseguidos pelo mesmo. Dessa maneira a questão da tolerância entrou em pauta no parlamento inglês.

Locke, esteve fortemente ligado aos whigs, opositores do absolutismo monárquico. Os seus Dois tratados sobre o governo trataram, sobretudo, de refutar a defesa do absolutismo monárquico pela via patriarcal elaborada por Robert Filmer na obra Patriarcha. Na Carta sobre a tolerância, que veio a público em 1689, mesmo ano dos Dois tratados, Locke, por assim dizer, desfere mais um golpe contra o modelo monárquico absolutista ao defender que ao Estado não cabe cuidar de assuntos religiosos. O objetivo de Locke (1987, p. 92)na Carta, como ele mesmo diz, era "definir os limites exatos entre a Igreja e o Estado".

Assim, muito embora a argumentação de Locke em defesa da tolerância seja mais ampla, envolvendo até mesmo elementos teológicos ${ }^{1}$, para este trabalho sobretudo nos interessará o terceiro argumento ao qual Locke recorre, qual seja, a necessidade de institucionalizá-la, o que implica separação entre igreja e Estado.

O Estado não pode cuidar das questões que dizem respeito à salvação da alma, porque seu poder consiste essencialmente na coação. Locke separa a coação característica do Estado da conversão, a conversão interior, característica da religião:

\begin{abstract}
o cuidado das almas não pode pertencer ao magistrado civil, porque todo o seu poder reside na coação. Mas, como a religião verdadeira e salutar consiste na fé interior da alma [...] a natureza do entendimento humano é tal que não pode ser constrangido por nenhuma força exterior. Confisquem-se os bens ou atormente-se o corpo com a prisão e a tortura, isso será em vão se, mediante esses suplícios, quiserdes alterar o juízo do espírito sobre as coisas. (LOCKE, 1987, p. 93, grifos nossos).
\end{abstract}

Não há uma verdadeira conversão sem que haja o sincero assentimento aos pressupostos religiosos. E tampouco pode o Estado determinar qual religião devem os indivíduos professar. Isso porque o poder de coação, tipicamente estatal, não pode alterar as crenças internas de cada um e, para Locke (1987, p.102), "nem o cuidado do Estado, nem o direito de legislar permitem ao magistrado descobrir com mais certeza o caminho que leva ao céu do que a um particular a sua reflexão e o seu estudo". Além do mais, um governante não é

\footnotetext{
${ }^{1}$ Segundo Antônio Carlos dos Santos (2014), há, na Carta, "três fortes argumentos a favor da tolerância", o primeiro de caráter teológico, segundo o qual a tolerância estaria de acordo com o evangelho; o segundo, de natureza política, defende que a diversidade de opiniões não deve ser causa de conflitos na sociedade; e, finalmente, o terceiro, "mais institucional", implica separação entre igreja e Estado, e delimita os papéis de cada um na sociedade.
} 
melhor em reconhecer a verdadeira religião do que cada um dos indivíduos, segundo suas convicções interiores: "os príncipes nascem maiores pelo poder, mas iguais por natureza ao resto dos mortais; o direito ou a arte de governar não trazem consigo o conhecimento certo das restantes coisas e, sobretudo, da verdadeira religião" (LOCKE, 1987, p.103).

E ainda que haja uma "igreja do rei", para Locke (1987, p. 106) não deve haver diferença entre ela e as demais religiões:

\footnotetext{
Chamo igrejas às sociedades religiosas que o magistrado deve tolera, porque não se trata, para o povo assim reunido em assembleias, senão do que é permitido e lícito a cada homem, isto é, ocupar-se da salvação da sua alma: e, neste ponto, não há nenhuma diferença entre a igreja do rei e a dos outros.
}

A tolerância, dessa forma, implica que o poder político se abstenha de impor uma determinada religião aos súditos e, além disso, implica também que cada súdito, cada indivíduo, cada membro da sociedade aceite as outras formas de culto que não a dele próprio: "nenhuma pessoa privada deve de modo algum lesar ou destruir os bens civis de outrem sob pretexto de professar outra religião ou praticar outros ritos. Todos os seus direitos de humanidade e de cidadania lhe devem ser conservados como sagrados" (LOCKE, 1987, p. 97).

A separação entre Igreja e Estado causa um deslocamento da religião enquanto delimitação do Estado para a religião enquanto delimitação individual. No momento em que a tolerância é institucionalizada, ou seja, no momento em que a tolerância passa a ser um princípio de Estado, nasce a liberdade para os indivíduos se definirem por religiões distintas. A multiplicidade religiosa não compromete os direitos do cidadão, nem gera privilégios: "se um judeu não crê que o Novo Testamento é a palavra de Deus, [isso] não altera nenhum direito civil" (LOCKE, 1987, p. 113).

O deslocamento da religião da esfera estatal para a esfera individual, entretanto, quebra a organicidade da vida política pois estabelece a separação entre indivíduo e Estado e entre sociedade e Estado. Esse estranhamento se consolida no fato de o Estado não permitir que os indivíduos professem várias religiões. Quando os indivíduos se determinam através da religião frente ao Estado, a separação, o estranhamento e a oposição Estado - indivíduo e Estado - sociedade se consolida. 


\title{
II
}

A institucionalização da tolerância, que implica indiferença do Estado em relação à religião professada por cada indivíduo, representa, para Marx, a migração da religião do Estado para a sociedade civil burguesa, da qual o indivíduo é parte. Essa migração da religião do Estado para a sociedade civil burguesa, por sua vez, é, segundo Marx, a própria emancipação política: “o deslocamento da religião do Estado para a sociedade burguesa, não constitui um estágio, e sim a realização plena da emancipação política" (MARX, 2010b, p.42, grifo nosso). O Estado torna-se alheio às questões religiosas e delega à sociedade civil a competência para tratar de questões dessa natureza. Assim, os assuntos religiosos deixam de pertencer à esfera do público e passam a pertencer à esfera do privado. A sociedade deixa de ter sua unidade política expressa por uma única religião que é comum a todos os indivíduos e passa a contar com várias religiões sem que qualquer delas seja a religião do Estado:

\begin{abstract}
O homem se emancipa politicamente da religião, banindo-a do direito público para o direito privado [...] [a religião] passou a ser o espírito da sociedade burguesa, a esfera do egoísmo, do bellum omnium contra omnes. [...] Ela não é mais a essência da comunidade, mas a essência da diferença. Ela se tornou expressão da separação entre o homem e sua comunidade, entre si mesmo e os demais homens - como era originalmente. (MARX, 2010b, p. 41-42).
\end{abstract}

Ao deslocar-se do Estado político para a sociedade civil, a religião não deixa de fazer parte da realidade dos indivíduos, mas apenas cessa a existência de uma religião de Estado enquanto traço da unidade social. O indivíduo não deixa de ser religioso em função de ser súdito de um Estado secular; de outra forma, passa a ter liberdade para professar a confissão religiosa que melhor lhe aprouver segundo suas íntimas convicções individuais. Dessa maneira, a tolerância como um valor social promovido pelo Estado está diretamente relacionada à emancipação política ${ }^{2}$, algo, para Marx, desejável, mas que não basta, pois embora emancipe politicamente, ainda não representa a completa emancipação humana. Não por acaso, Marx (2010b, p. 36) acusa Bauer de ter feito uma "confusão acrítica da emancipação política com a emancipação humana geral".

Isso porque, para Marx, o que realmente deveria estar em primeiro plano não era a mera emancipação política, através da indiferença estatal, mas a própria emancipação humana

\footnotetext{
${ }^{2}$ Sobre isso, afirma Bobbio (1979, p. 21): "Marx sabia muitíssimo bem [...] que um dos traços fundamentais e verdadeiramente inovadores da revolução francesa era a proclamação da igualdade jurídica ou igualdade diante da lei, a chamada igualdade formal (a 'emancipação política’!) ”.
} 
frente ao Estado que, para Marx, era um instrumento burguês por excelência, era a ferramenta da qual o homem burguês se utilizava para impor seus valores e seu modo de vida ${ }^{3}$. Anuímos aqui ao seguinte comentário de Lukácks (2009, p. 165), segundo o qual a emancipação política: “é apenas um progresso no interior do 'atual ordenamento do mundo', enquanto [..] a emancipação humana, pressupõe [...] a negação 'da auto alienação humana' e, portanto, um ordenamento fundamentalmente novo da sociedade". Assim, para além da emancipação no Estado, deveria ser preferida a emancipação do Estado:

A emancipação política de fato representa um grande progresso; não chega a ser a forma definitiva de emancipação humana em geral, mas constitui a forma definitiva de emancipação humana dentro da ordem mundial vigente até aqui. (MARX, 2010b, p. 41, grifo nosso)

Como fica claro na passagem, Marx reconhece "um grande progresso" na possibilidade de haver várias religiões, todas elas livres da imposição do Estado; em outras palavras, é um ganho para a vida política que seja possível praticar qualquer religião sem que se percam os direitos políticos frente ao Estado. Locke (1987, p. 105) acreditava haver liberto “os homens do domínio que exercem uns sobre os outros em matéria de religião", através da tolerância defendida em sua Carta. O verdadeiro problema, entretanto, para Marx não é se o Estado deve tolerar essa ou aquela igreja, ou se ele deve garantir direitos políticos a cidadãos independentemente da religião que professam; o verdadeiro problema preconizado por Marx (2010b, p. 41) é a "emancipação real, [e] prática", do indivíduo. Assim, não basta o Estado tolerar diversas religiões pois tanto a existência das religiões quanto a existência do próprio Estado tornam impossível a verdadeira emancipação humana. Por isso a religião é metaforicamente tratada como uma "pele de cobra" que deve ser expelida através da história:

\begin{abstract}
Assim que judeu e cristão passarem a reconhecer suas respectivas religiões tão somente como estágios distintos do desenvolvimento do espírito humano - como diferentes peles de cobra descartadas pela história, e reconhecerem o homem como a cobra que nelas trocou de pele, eles não se encontrarão mais em uma relação religiosa, mas apenas em uma relação crítica, científica, em uma relação humana. A ciência constitui então sua unidade. (MARX, 2010b, p. 34, grifo nosso).
\end{abstract}

Apesar de não se rejeitar completamente o "progresso" da emancipação política, da tolerância do Estado para com a diversidade de confissões religiosas, é preciso ainda que se

\footnotetext{
${ }^{3}$ Segundo Bobbio (1979, p.29): "Marx tem uma concepção instrumental do Estado - o Estado como aparato a serviço da classe dominante".
} 
atinja a verdadeira emancipação humana: "pelo fato de poderdes vos emancipar politicamente sem vos desvincular completa e irrefutavelmente do judaísmo, a emancipação política não é por si mesma a emancipação humana" (MARX, 2010b, p. 46).

Para deixar mais clara a crítica que Marx faz à emancipação política, é preciso explorar um pouco mais sua ideia de emancipação humana, o tipo de emancipação que Marx privilegia definitivamente. Sobre isso afirma Marx (2010b, p. 54) que "toda emancipação é restituição do mundo humano e suas relações ao próprio homem ${ }^{4}$. . Esse caráter restituidor sugere o retorno de algo que foi retirado dos homens. Trata-se do próprio mundo essencialmente humano que foi desfeito pela forma burguesa de sociedade. Lembramos que segundo Marx (2010a, p. 75-76):

\begin{abstract}
A essência humana é a verdadeira comunidade humana. E assim como o desesperado isolamento dela é incomparavelmente mais universal, insuportável, pavoroso e contraditório, do que o isolamento da comunidade política, assim também a supressão desse isolamento e até uma reação parcial, uma revolta contra ele, é tanto mais infinita quanto infinito é o homem em relação ao cidadão e a vida humana em relação à vida política.
\end{abstract}

Mesmo a emancipação política é insuficiente para restituir aos indivíduos a vida conforme sua essência. A tolerância, a igualdade, a liberdade e tantos outros valores do Estado burguês não bastam para restituir o verdadeiro mundo humano aos homens. E, além disso, os valores do Estado burguês, segundo Marx, consolidam os seres humanos na sua forma de ser individualista. A tolerância seria como uma espécie de ratificação das diferenças (religiosas) pelo Estado: “A emancipação política é a redução do homem, por um lado, a membro da sociedade burguesa, a indivíduo egoísta independente, e, por outro, a cidadão, a pessoa moral" (MARX, 2010b, p. 54). A separação do Estado - entendido como a esfera espiritual - da sociedade civil-burguesa - entendida, por sua vez, como esfera material da vida política - se reflete na divisão do indivíduo "em um citoyen espiritual e um bourgeois material, em um membro do Estado, e um indivíduo vivo" (LUKÁCS, 2009, p. 167).

O que Marx queria, ao condenar a emancipação política, era justamente a efetivação dos direitos meramente formais concedidos pelo Estado burguês. Esses direitos, entretanto, não poderiam se efetivar enquanto o homem tivesse sua existência repartida em duas faces opostas: a do cidadão político, genérico e abstrato (citoyen) e a do homem burguês, natural e egoísta (bourgeois) (LUKÁCS, 2009, p. 167).

\footnotetext{
${ }^{4}$ Optamos por alterar a tradução do termo "Zurückführung", utilizado no original alemão, para "restituição" em vez de "redução" (Reduktion), conforme consta na edição brasileira aqui utilizada.
} 
Isso porque o Estado, dentro dessa estrutura social, seria um simples meio para preservar os direitos do bourgeois (liberdade, propriedade), direitos esses que consolidam a existência parcial, individual; e possibilitam aos homens se explorarem e dominarem uns aos outros, em detrimento do citoyen, o homem genérico e político:

a esfera em que o homem se comporta como ente comunitário é inferiorizada em relação àquela em que ele se comporta como ente parcial; quando vemos, por fim, que não o homem como citoyen,, mas o homem como bourgeois é assumido como o homem propriamente dito e verdadeiro. (MARX, 2010b, p. 50).

É necessário então, a fim de efetivar a verdadeira emancipação humana para além dos meros direitos formais, reunir em uma só pessoa o que a sociedade burguesa separou: o citoyen e o bourgeois, para que o homem natural e individual se torne também o homem genérico, político e moral. Esse é o significado da restituição do mundo humano ao homem:

a emancipação humana só estará plenamente realizada quando o homem individual
real tiver recuperado para si o cidadão abstrato e se tornado ente genérico na
qualidade de homem individual na sua vida empírica, no seu trabalho individual, nas
suas relações individuais, quando o homem tiver reconhecido e organizado suas
"forces propres" [forças próprias] como forças sociais e, em consequência, não mais
separar de si mesmo a força social na forma de força política. (MARX, 2010b, p. 54,
grifo do autor).

\section{CONSIDERAÇÕES FINAIS}

O presente trabalho tratou de dois importantes textos da história da filosofia para, através da análise comparativa, trazer à luz a posição defendida em diferentes momentos acerca da questão religiosa frente ao Estado político. A proposta inicial foi responder, segundo Locke e depois Marx, à questão: "qual deve ser o lugar da religião no Estado político?"

Para Locke, a religião deve estar na sociedade civil, limitada por valores individuais como fé, e sentimento interior de cada um. Precisamente por enxergar no Estado uma espécie de "mal necessário", a preocupação maior de Locke é justamente estabelecer os limites da atuação estatal baseados na lei da natureza, que é anterior e maior que o próprio Estado. A religião abandona, assim, o Estado e migra para a esfera individual. Cada indivíduo passa a ter o direito de professar sua fé de acordo com seu sentimento interior, ou seja, levando em consideração sua individualidade. Dessa maneira, é selada a separação entre o Estado e a religião, entre a esfera política e a esfera religiosa. 
Esse deslocamento da religião para o plano da sociedade civil, consolida, para Marx, a emancipação política do indivíduo; porém não representa a emancipação final, a emancipação humana. Emancipar-se humanamente implica superação da religião como determinação individual. O homem religioso é ainda um homem parcial, fracionado em cristão, judeu etc.; a emancipação verdadeira representaria a superação da determinação religiosa pela qual os homens poderiam se reconhecer apenas como homens, apenas como o homem genérico. Não apenas deve-se superar a religião, como também o Estado político contraposto à sociedade. Nessa circunstância, o cidadão (citoyen), o homem do Estado, o homem genérico, é apenas um ser simbólico, uma figura alegórica. Enquanto, por outro lado, o homem material (bourgeois) vive na sociedade civil onde pode firmar sua tendência egoísta e individualista. A tolerância religiosa acaba por promover o tipo de conduta que culmina no individualismo do “cada um tem sua religião".

Por isso, segundo Marx, enquanto houver religião e enquanto houver Estado político, o homem jamais será completamente emancipado. A religião - e também o Estado - devem ser como a "pele da serpente", abandonada durante o desenvolvimento histórico.

\section{REFERÊNCIAS}

BOBBIO, Norberto. [et al.] O marxismo e o estado. Tradução Federica L. Boccardo e Renee Levie. Rio de Janeiro: Graal, 1979.

LOCKE, John. Carta sobre a tolerância. Tradução João da Silva Gama. Lisboa: Edições 70, 1987.

LUKÁCS, György. O jovem Marx e outros escritos de filosofia. Tradução Carlos Nelson Coutinho e José Paulo Netto. 2. ed. Rio de Janeiro: Editora da UFRJ, 2009.

MARX, Karl. Glosas críticas marginais ao artigo "O rei da Prússia e a reforma social": de um prussiano. Tradução Ivo Tonet. São Paulo: Expressão Popular, 2010a.

MARX, Karl. Sobre a questão judaica. Tradução Nélio Schneider, Daniel Bensaid e Wanda Caldeira Brant. São Paulo: Boitempo, 2010b.

SANTOS, Antônio Carlos. Os elementos republicanos na tolerância de John Locke.

Kriterion, on line, vol 55, n.130, Belo Horizonte: dez. 2014. Disponível em http://www.scielo.br/scielo.php?script=sci_arttext\&pid=S0100512X2014000200003. Acesso em: 07 jan. de 2018. ISSN: 0020-3653. 